\title{
Estrutura Ontológica para representar Papéis Colaborativos Afetivos em ambientes CSCL
}

\section{Title: Ontological Structure to represent Affective Collaborative Learning Roles in CSCL Environments}

\author{
Rachel Carlos Duque Reis \\ Universidade de São Paulo (ICMC - USP) - Brasil \\ Universidade Federal de Viçosa (UFV - CRP) - Brasil \\ rachel.reis@ufv.br
}

Kamila Takayama Lyra

Universidade de São Paulo (ICMC - USP) - Brasil

kalyra_03@usp.br

\author{
Carla Lopes Rodriguez \\ Universidade Federal do ABC (CMCC-UFABC)-Brasil \\ c.rodriguez@ufabc.edu.br
}

\author{
Seiji Isotani \\ Universidade de São Paulo (ICMC - USP) - Brasil \\ sisotani@icmc.usp.br
}

\begin{abstract}
Resumo
O uso de ontologias para representar os cenários CSCL tem sido investigado por diversos pesquisadores na literatura. Apesar das importantes contribuições desses trabalhos, observou-se a carência de estudos que consideram os aspectos ligados a afetividade do aluno, como os traços de personalidade, na representação desses cenários. Logo, este artigo tem como objetivo ampliar a estrutura ontológica de Papéis Colaborativos Afetivos (PCA) representando a relação entre os traços de personalidade Extrovertido Estável/Instável e o papel de Participante Pleno pertencente à teoria de aprendizagem Distributed Cognition. Com base nessa estrutura ontológica foram criados três cenários CSCL para lidar com a falta de reflexão dos estudantes. No intuito de avaliar o impacto da característica de baixa e alta impulsividade nesses cenários, foi desenvolvido um estudo de caso com crianças entre 09 e 10 anos para verificar três hipóteses alternativas. Os resultados mostraram indícios de que a característica de baixa impulsividade em grupos homogêneos, em que todos os membros desempenham o PCA Participante Pleno Extrovertido Estável, não afeta negativamente a performance do grupo. Espera-se com base nessa estrutura contribuir para a ampliação de soluções para a construção de cenários CSCL mais efetivos e personalizados.
\end{abstract}

Palavras-Chave: CSCL; Traço de Personalidade; Teoria de Aprendizagem; Ontologia.

\begin{abstract}
The use of ontologies to represent CSCL scenarios have been investigated by several researchers in the literature. Despite of important contributions of such works, we have observed the lack of studies that consider the aspects related to students' affect (e.g., personality trait) to represent such scenarios. Thus, this paper aims at extending the ontological structure of Affective Collaborative Learning (ACL) role to represent the relation between Stable/Unstable Extroverted personality traits and Full Participant role defined by the Distributed Cognition learning theory. Based on such ontological structure we create three CSCL scenarios to deal with lack of students' reflection. In order to evaluate the impact of low and high impulsivity characteristics on such scenarios, we developed a case study with children aged between 09-10 to verify three alternative hypotheses. The results indicate that low impulsivity in homogeneous groups, where students performed the ACL role Extroverted Stable Full Participant, does not influence the group performance. Based on such ontological structure we hope to contribute with solutions to create more effective and personalized CSCL scenarios.
\end{abstract}

Keywords: CSCL; Personality Trait; Learning Theory; Ontology.

Cite as: Reis, R. C. D., Rodriguez, C. L., Lyra, K. T. \& Isotani, S.. (2017). Ontological Structure to represent Affective Collaborative Learning Roles in CSCL Environments (Estrutura Ontológica para representar Papéis Colaborativos Afetivos em ambientes CSCL). Brazilian Journal of Computers in Education (Revista Brasileira de Informática na Educação - RBIE), 25(2), 87-106. DOI: 10.5753/RBIE.2017.25.02.87 


\section{Introdução}

Dado que a colaboração espontânea (free collaboration) entre os participantes de um grupo não assegura os ganhos de aprendizagem dos seus membros, especialistas da aprendizagem colaborativa (Dillenbourg, 2002; Kobbe et al., 2007; Isotani et al., 2013; Challco, Moreira, Bittencourt, Mizoguchi, \& Isotani, 2015) têm se concentrado em desenvolver soluções computacionais para apoiar o planejamento e a criação de cenários CSCL (Computer Supported Collaborative Learning - sigla em inglês para Aprendizagem Colaborativa com Suporte Computacional) mais efetivos. Nesse contexto, as ontologias computacionais se apresentam como uma interessante solução ao possibilitar: 1) a representação de um domínio de conhecimento com potencial de reutilização; 2) a formalização do domínio livre de contradições, ambiguidades e inconsistências na representação do conhecimento; e 3) o compartilhamento do conhecimento entre pessoas e/ou aplicações computacionais (Gruber, 1993; Borst, 1997; Mizoguchi, 2003).

Apesar das importantes contribuições das pesquisas sobre o uso de ontologias para representar e descrever os ambientes e cenários CSCL (Inaba, Ikeda, \& Mizoguchi, 2003; Inaba \& Mizoguchi, 2004; Isotani, Inaba, Ikeda, \& Mizoguchi, 2009; Isotani et al., 2013; Challco et al., 2015), observou-se que os aspectos afetivos, importantes para o engajamento motivacional e para regular as interações dos alunos (Dillenbourg, Järvelä, \& Fischer, 2009), não têm sido considerados nesses estudos. Nesse sentido, o presente trabalho tem como objetivo ampliar a estrutura ontológica de Papéis Colaborativos Afetivos (PCAs) definida por Reis, Rodriguez, Challco et al. (2015) e Reis, Rodriguez, Lyra, Challco et al. (2016) para representar a relação entre os traços de personalidade e as teorias de aprendizagem colaborativas ${ }^{1}$. Especificamente neste trabalho serão combinados os traços de personalidade extrovertido estável/instável (Sisto, 2004) e o papel colaborativo Participante Pleno (full participant) pertencente a teoria de aprendizagem Distributed Cognition (Salomon, 1993). Como resultado dessa relação tem-se os PCAs Participante Pleno Extrovertido Estável e Participante Pleno Extrovertido Instável. Com base nessa estrutura ontológica espera-se viabilizar o planejamento e a construção de cenários CSCL mais efetivos para lidar, por exemplo, com a pouca ou ausência de reflexão dos estudantes, decorrente das características de alta e baixa impulsividade inerentes aos traços de personalidade.

No intuito de avaliar três cenários de colaboração foi desenvolvido um estudo de caso envolvendo 18 alunos do $5^{\circ}$ ano do Ensino Fundamental I para verificar se as seguintes hipóteses alternativas se confirmam:

H1.1) Em grupos com PCAs homogêneos, em que todos os membros desempenham o papel de participante pleno extrovertido estável, a característica de baixa impulsividade é prejudicial se pelo menos um dos membros manifestá-la durante a sessão colaborativa.

H1.2) Em grupos com PCAs homogêneos, em que todos os membros desempenham o papel de participante pleno extrovertido instável, a característica de alta impulsividade é prejudicial se pelo menos um dos membros manifestá-la durante a sessão colaborativa.

H1.3) Em grupos com PCAs heterogêneos, quando os membros desempenham os papéis de participante pleno extrovertido estável e participante pleno extrovertido instável, as características de baixa e/ou alta impulsividade prejudicam a performance do grupo se pelo menos um dos membros manifestar uma dessas características durante a sessão colaborativa.

\footnotetext{
${ }^{1}$ Este trabalho é uma extensão do artigo publicado por Reis, Rodriguez, Lyra, e Isotani (2016).
} 
Além dessa seção introdutória, este trabalho está organizado da seguinte forma: na Seção 2 são apresentados os trabalhos relacionados. Na sequência, a Seção 3 apresenta a síntese da bibliografia fundamental, que oferece uma explicação sobre os principais conceitos usados neste trabalho. A Seção 4 apresenta o método utilizado para relacionar os traços de personalidade extrovertido estável e extrovertido instável (Sisto, 2004) ao papel de Participante Pleno (Salomon, 1993). A Seção 5 apresenta a estrutura ontológica com os novos PCAs e três exemplos de cenário CSCL para lidar com a pouca ou ausência de reflexão dos estudantes. A Seção 6 apresenta um estudo de caso para validar os cenários CSCL e, finalmente, na Seção 7 são apresentadas as conclusões.

\section{Trabalhos Relacionados}

De acordo com Dillenbourg (2002), soluções computacionais como os "scripts de colaboração" definem um conjunto de instruções (diretrizes) que descrevem o processo para formação de grupos, interação e colaboração entre os alunos e resolução de problemas. Além disso, esses scripts permitem a descrição de cenários de aprendizagem colaborativa envolvendo diferentes componentes (e.g., participantes, atividades, papéis, recursos e grupos) e mecanismos (e.g., distribuição de tarefas, formação de grupos e sequenciamento de interação) para a condução do processo de colaboração (Kobbe et al., 2007).

Apesar dos benefícios do uso dos scripts de colaboração na criação e estruturação dos cenários CSCL, Challco et al. (2015) apresentam o problema de falta de motivação dos alunos nesses ambientes, o que pode afetar a qualidade das interações e prejudicar a realização de atividades a longo prazo. No intuito de minimizar o problema, os autores propõem a criação de cenários colaborativos gamificados ${ }^{2}$, representados por meio de ontologias, como uma iniciativa para a construção de cenários colaborativos mais personalizados e que promovam o engajamento e a motivação dos alunos.

Isotani et al. $(2009,2013)$ sinalizam que os scripts de colaboração nem sempre são claros na definição da estratégia pedagógica a ser adotada, o que acaba dificultando sua adoção por parte dos educadores. Esse problema ocorre devido à diversidade de teorias de aprendizagem usadas para favorecer o processo de formação, planejamento das atividades e análise dos grupos de trabalho. Nesse contexto, Isotani et al. (2009) apresentam uma estrutura ontológica (ontological framework), baseada nas teorias de aprendizagem colaborativas (e.g. Distributed Cognition (Salomon, 1993)), para orientar a formação de grupos e o planejamento instrucional das atividades colaborativas. Nesse trabalho, a estrutura ontológica provê a formalização necessária para representar os cenários de aprendizagem colaborativa, já as teorias de aprendizagem servem de suporte às decisões pedagógicas para, por exemplo, agrupar os estudantes e planejar os cenários de colaboração. Dando continuidade ao trabalho anterior, Isotani et al. (2013) apresentam CHOCOLATO (a Concrete and Helpful Ontology-aware COllaborative Learning Authoring Tool), um sistema de autoria "inteligente", com capacidade para representar, por meio de ontologias, diferentes teorias de aprendizagem e prover o suporte necessário para a criação de cenários CSCL.

Dada a importância de considerar os aspectos afetivos na projeção dos cenários CSCL (Dillenbourg et al., 2009) e a carência de estudo nessa área (Reis, Rodriguez, Lyra et al., 2015), este trabalho visa contribuir para a ampliação de representações computacionais baseadas em

\footnotetext{
${ }^{2}$ Os cenários colaborativos gamificados consistem na combinação dos cenários de aprendizagem colaborativa com técnicas de gamificação usada para motivar e engajar os estudantes durante o trabalho em grupo (Challco et al., 2015).
} 
ontologias que utilizem os traços de personalidade combinados às teorias de aprendizagem colaborativas para o planejamento e criação de cenários CSCL mais efetivos e personalizados.

\section{Bibliografia Fundamental}

Esta seção introduz os principais conceitos relacionados ao desenvolvimento deste trabalho, são eles: traços de personalidade, teorias de aprendizagem colaborativas e ontologias CSCL.

\subsection{Traços de Personalidade}

Uma das dificuldades enfrentadas pelos estudos que trabalham com afetividade é a definição para os diversos termos a ela associados (Longhi, Reateagui, Bercht, \& Behar, 2007). No contexto dos traços de personalidade, Jaques e Nunes (2012) apresentam a visão de diferentes pesquisadores e concluem que os traços não são permanentes e imutáveis conforme apresentado por alguns estudos. Para Scherer (2005), os traços de personalidade com essência afetiva (e.g., ansiedade, ciúmes) são definidos como disposições afetivas (affective disposition), capazes de descrever a tendência de uma pessoa experimentar com maior ou menor frequência determinado estado de ânimo ou reagir a um estímulo com certos tipos de emoção.

Neste estudo, os traços de personalidade são definidos como tendências comportamentais (Pacheco \& Sisto, 2003) que são comuns a todas as pessoas e individuais a cada ser humano (Allport, 1927). Dessa forma, a intensidade pela qual os traços de personalidade são expressos varia de pessoa para pessoa e, em geral, está relacionada ao grau em que as características do traço se manifesta em um indivíduo. Por exemplo, dois indivíduos podem ter o traço de "extroversão", e cada um possuir um nível de "extroversão" diferente. Essas diferenças, em geral, estão relacionadas ao grau em que as características do traço (e.g., impulsividade, ansiedade) se manifesta no sujeito.

\subsection{Teorias de Aprendizagem Colaborativas}

$\mathrm{Na}$ visão de Piaget, o processo de colaboração é essencial para o desenvolvimento e aprendizagem dos alunos, pois a partir dessa interação ocorre o "desequilíbrio" também conhecido como "conflito cognitivo" que leva o indivíduo à construção de novos conhecimentos. Vigotsky complementa ao afirmar que para a aprendizagem ser efetiva, essa interação deve ocorrer dentro da zona de desenvolvimento proximal, que consiste na distância entre aquilo que o aluno já conhece e aquilo que ele possui potencial para aprender (Moreira, 1995).

No contexto da CSCL, Isotani et al. (2009) apresentam as teorias de aprendizagem colaborativas como um fator essencial para guiar o processo de colaboração no trabalho em grupo. Essas teorias determinam o contexto para desenvolvimento da atividade de aprendizagem, o tipo de conhecimento e habilidade a ser desenvolvida, e o papel a ser desempenhado pelos aprendizes. Dessa forma, elas podem ser usadas nos diversos cenários CSCL para apoiar e justificar pedagogicamente a seleção dos estudantes para a formação dos grupos de aprendizagem.

Neste trabalho será utilizada a teoria de aprendizagem colaborativa Distributed Cognition (Salomon, 1993) que determina que todos os membros de um grupo sejam participantes centrais, ou seja, desempenhem o mesmo papel de Participante Pleno (full participant). Como estratégia de aprendizagem a teoria sugere que as interações sejam realizadas de forma que os alunos apresentem soluções e críticas construtivas para os problemas propostos e compartilhem ideias. Individualmente, essa teoria tem como objetivo melhorar os 
conhecimentos e as habilidades do aluno em resolver problemas complexos e apresentar ideias de forma clara e concisa.

\subsection{Ontologias CSCL}

De acordo com Borst (1997, p. 12) uma ontologia é definida como uma "especificação formal e explícita de uma conceitualização compartilhada". O termo formal se refere a algo que seja compreensível por computadores; especificação explícita diz respeito a conceitos, propriedades, relações, funções, restrições, axiomas, explicitamente definidos; e compartilhada significa conhecimento consensual entre pessoas e/ou aplicações computacionais.

O uso de ontologias para o desenvolvimento de soluções computacionais no contexto educacional tem sido investigado por diversos pesquisadores na literatura (Dicheva, Sosnovsky, Gavrilova, \& Brusilovsky, 2005; Mizoguchi, Sunagawa, Kozaki, \& Kitamura, 2007; Isotani \& Mizoguchi, 2007; Bittencourt \& Costa, 2011; Romo, Guilherme, \& Queiroz, 2013). Na área da CSCL, o trabalho desenvolvido por Inaba, Supnithi, Ikeda, e Mizoguchi (2000) foi um dos primeiros a usar ontologias com a proposta de definir um vocabulário padrão para descrever os cenários de aprendizagem colaborativa. A partir desse trabalho, outros estudos foram conduzidos, no intuito de melhorar os cenários CSCL, a partir da criação de modelos e desenvolvimento de estratégias para dar suporte ao planejamento das atividades colaborativas, à formação de grupos, e ao engajamento e interação entre os alunos (Inaba et al., 2003; Inaba \& Mizoguchi, 2004; Isotani \& Mizoguchi, 2007; Isotani et al., 2009, 2013; Challco et al., 2015).

Apesar das importantes contribuições das pesquisas sobre o uso de ontologias para representar e descrever os ambientes e cenários CSCL, observou-se que os estados afetivos não têm sido considerados nas modelagens desenvolvidas. Logo, nesse trabalho, o conceito de ontologias será usado para representar novos Papéis Colaborativos Afetivos definidos a partir da relação entre os traços de personalidade Extrovertido Estável/Instável (Sisto, 2004) e o papel de Participante Pleno (Salomon, 1993).

\section{Método para Criação dos Papéis Colaborativos Afetivos (PCAs)}

Esta seção descreve o método utilizado para relacionar os traços de personalidade Extrovertido Estável e Extrovertido Instável (Sisto, 2004) à teoria de aprendizagem Distributed Cognition (Salomon, 1993), que dará origem a novos Papéis Colaborativos Afetivos (PCAs). Esse método, definido por Reis, Rodriguez, Challco et al. (2015) e Reis, Rodriguez, Lyra, Challco et al. (2016) é composto por quatro etapas, que são detalhadas nas próximas subseções: i) determinar as características do traço de personalidade; ii) identificar as características dos traços de personalidade que podem influenciar negativamente o comportamento dos estudantes; iii) definir os novos PCAs com base nos traços de personalidade definidos; e iv) estabelecer estratégias para assegurar os benefícios de aprendizagem dos estudantes.

\subsection{Determinar as características dos traços de personalidade}

Neste trabalho serão utilizados os traços de personalidade denominados de Extrovertido Estável e Extrovertido Instável, derivados da combinação das características dos traços de extroversão e neuroticismo apresentada por Sisto (2004). As características de cada um dos traços de personalidade utilizados neste trabalho são apresentadas na Tabela 1. 
Tabela 1: Características dos traços de personalidade Extrovertido Estável e Extrovertido Instável. Fonte: Sisto (2004).

\begin{tabular}{|c|c|}
\hline Traços de Personalidade & Características \\
\hline Extrovertido Estável & $\begin{array}{c}\text { Sociável, comunicativo, receptivo, líder, descontraído, } \\
\text { animado, despreocupado, baixa impulsividade. }\end{array}$ \\
\hline Extrovertido Instável & $\begin{array}{c}\text { Ansioso, tenso, depressivo, preocupado, nervoso, } \\
\text { inquieto, instável emocionalmente, melancólico, baixa } \\
\text { autoestima, alta impulsividade. }\end{array}$ \\
\hline
\end{tabular}

Com base no manual do teste de personalidade ETPC (Escala de Traços de Personalidade para Crianças) (Sisto, 2004), um indivíduo será caracterizado como Extrovertido Estável quando no resultado do teste, sua classificação para o traço de extroversão for maior ou igual a $75 \%$ e neuroticismo menor ou igual a $25 \%$. Por outro lado, um indivíduo será caracterizado como Extrovertido Instável quando no resultado do teste sua classificação para os traços de neuroticismo e extroversão for maior ou igual a $75 \%$.

\subsection{Identificar as características dos traços de personalidade que podem prejudicar o comportamento dos estudantes}

Com base na Tabela 1, as características de baixa e alta impulsividade, pertencentes respectivamente aos traços de personalidade Extrovertido Estável e Extrovertido Instável, foram isoladas no intuito de verificar a influência desses elementos no comportamento dos alunos em uma situação colaborativa de aprendizagem.

Segundo Vaz (2005), a impulsividade é definida por três comportamentos básicos de um indivíduo: o agir sem pensar, respostas rápidas e a impaciência. Como resultado desses comportamentos um sujeito impulsivo quando colocado diante de uma situação problema, tende a dar respostas rápidas de forma não reflexiva e com maior número de erros.

\subsection{Definir os novos Papéis Colaborativos Afetivos (PCAs)}

Para a definição dos novos PCAs deve-se primeiramente conhecer as características do papel de Participante Pleno (full participant) pertencente à teoria de aprendizagem Distributed Cognition (Salomon, 1993). Essas características podem ser visualizadas na Tabela 2.

Tabela 2: Papel colaborativo de Participante Pleno e suas características. Fonte: Inaba e Mizoguchi (2004).

\begin{tabular}{|c|c|c|c|}
\hline $\begin{array}{c}\text { Papel } \\
\text { Colaborativo }\end{array}$ & Comportamento & Pré-requisitos & $\begin{array}{c}\text { Benefícios Educacionais } \\
\text { Esperados }\end{array}$ \\
\hline $\begin{array}{c}\text { Participante } \\
\text { Pleno }\end{array}$ & $\begin{array}{l}\text { Atitude para } \\
\text { resolução de } \\
\text { problemas. }\end{array}$ & $\begin{array}{l}\text { * Ter o conhecimento do conteúdo. } \\
\text { * Ter experiência em usar o conteúdo. } \\
\text { * Ter conhecimento relacionado no domínio. } \\
\text { * Saber como usar a habilidade cognitiva. } \\
\text { * Ter experiência em usar a habilidade } \\
\text { cognitiva. } \\
\text { * Saber como usar a habilidade meta-cognitiva. } \\
\text { * Ter experiência em usar a habilidade meta- } \\
\text { cognitiva. }\end{array}$ & $\begin{array}{l}\text { Aquisição de } \\
\text { conhecimento específico } \\
\text { do conteúdo. } \\
\text { Desenvolvimento da } \\
\text { habilidade cognitiva. } \\
\text { Desenvolvimento da } \\
\text { habilidade meta-cognitiva. }\end{array}$ \\
\hline
\end{tabular}

De acordo com a Tabela 2, os alunos que desempenham o papel de Participante Pleno (coluna 1) devem adotar o comportamento de atitude para resolução de problemas (coluna 2). No entanto, para que o aluno esteja apto a desempenhar esse papel, existem pré-requisitos (coluna 3) necessários sinalizados na Tabela $2 \mathrm{com}$ '*', ou seja, essenciais que devem ser atendidos. Por exemplo, (1) ter conhecimento sobre o conteúdo que será abordado, (2) ter experiência no uso desse conteúdo, (3) ter conhecimento sobre conteúdos relacionados, dentre outros. Dessa forma, quando um aluno desempenhar este papel espera-se que os seguintes benefícios educacionais de aprendizagem sejam alcançados (coluna 4): (1) aquisição de conhecimento específico do conteúdo, (2) desenvolvimento da habilidade cognitiva, e (3) desenvolvimento da habilidade meta-cognitiva. 
Uma vez que as características do papel de Participante Pleno são conhecidas (Tabela 2), especializações desse papel são definidas para a criação dos novos PCAs Participante Pleno Extrovertido Estável e Participante Pleno Extrovertido Instável conforme mostrado na Tabela 3.

De acordo com a Tabela 3, os alunos que desempenharem o PCA Participante Pleno Extrovertido Estável (coluna 1), além dos pré-requisitos definidos pelo papel de Participante Pleno (coluna 3, Tabela 2), deverão apresentar os pré-requisitos afetivos de alta extroversão e baixo neuroticismo (coluna 2, Tabela 3), ou seja, possuir o traço de personalidade Extrovertido Estável. Nesse caso, a característica de baixa impulsividade (coluna 3, Tabela 3) é vista como uma ameaça ao comportamento do estudante dado que ela pode ocasionar a falta de reflexão dos estudantes (coluna 4, Tabela 3) durante a resolução de problemas. Finalmente, os benefícios de aprendizagem esperados (coluna 5, Tabela 3) se mantém os mesmos apresentados na Tabela 2 (coluna 4). Vale ressaltar que, embora o desenvolvimento da habilidade meta-cognitiva seja um benefício previsto pela teoria de aprendizagem Distributed Cognition (Salomon, 1993), essa habilidade não foi medida no estudo de caso apresentado na Seção 6.

O mesmo raciocínio anterior deve ser seguido para os alunos que desempenharem o PCA Participante Pleno Extrovertido Instável (coluna 1, Tabela 2).

Tabela 3: Novos PCAs e suas características.

\begin{tabular}{|c|c|c|c|c|}
\hline PCA & $\begin{array}{l}\text { Pré-requisito } \\
\text { afetivo }\end{array}$ & $\begin{array}{c}\text { Característica } \\
\text { do traço que } \\
\text { pode ser uma } \\
\text { ameaça }\end{array}$ & $\begin{array}{l}\text { Comportamento } \\
\text { (problema) }\end{array}$ & $\begin{array}{c}\text { Benefícios de } \\
\text { aprendizagem esperados }\end{array}$ \\
\hline $\begin{array}{c}\text { Participante pleno } \\
\text { extrovertido } \\
\text { estável }\end{array}$ & $\begin{array}{l}\text { Alta extroversão. } \\
\text { Baixo neuroticismo. } \\
\text { * (Pré-requisitos da } \\
\text { Tabela 2) }\end{array}$ & $\begin{array}{c}\text { Baixa } \\
\text { impulsividade }\end{array}$ & \multirow{2}{*}{$\begin{array}{l}\text { Resolução de } \\
\text { problemas } \\
\text { (falta de } \\
\text { reflexão). }\end{array}$} & $\begin{array}{l}\text { Aquisição de conhecimento } \\
\text { específico sobre o conteúdo. } \\
\text { Desenvolvimento da } \\
\text { habilidade cognitiva. }\end{array}$ \\
\hline $\begin{array}{l}\text { Participante pleno } \\
\text { extrovertido } \\
\text { instável }\end{array}$ & $\begin{array}{l}\text { Alta extroversão. } \\
\text { Alto neuroticismo. } \\
\text { * (Pré-requisitos da } \\
\text { Tabela 2) }\end{array}$ & $\begin{array}{c}\text { Alta } \\
\text { impulsividade }\end{array}$ & & $\begin{array}{l}\text { Desenvolvimento da } \\
\text { habilidade meta-cognitiva. }\end{array}$ \\
\hline
\end{tabular}

\subsection{Estabelecer estratégias que assegurem os benefícios de aprendizagem}

Segundo Bidjerano e Dai (2007), indivíduos extrovertidos podem ter dificuldade em resolver problemas que requerem reflexão. Em geral, a dificuldade de reflexão mais profunda pode ocasionar a tomada de decisões cognitivas de forma prematura. Dessa forma, no intuito de assegurar os benefícios educacionais de aprendizagem para os alunos que desempenharem os PCAs Participante Pleno Extrovertido Estável e Participante Pleno Extrovertido Instável recomenda-se o uso de estratégias que promovam a verbalização e incentivem a reflexão dos alunos. Por exemplo, utilizar estratégias como Brainstorming e Thinking Aloud (Huitt, 1992) ou técnicas que estimulem a reflexão, como pausa de 5-10 segundos para analisar uma determinada solução (Davidson, Gillies, \& Pelletier, 2015).

\section{Estrutura Ontológica - novos Papéis Colaborativos Afetivos (PCAs)}

A Figura 1 apresenta a estrutura ontológica de papéis (CL Role) definida por Isotani et al. (2009) que será usada para representar os novos PCAs Participante Pleno Extrovertido Estável e Participante Pleno Extrovertido Instável, definidos na Seção 4.

De acordo com a Figura 1(a), a estrutura ontológica que representa um papel colaborativo de aprendizagem ( $C L$ Role) é composta pelos pré-requisitos que o aluno deve possuir para desempenhar determinado papel, definidos como condições necessárias (necessary 
condition) e condições desejadas (desired condition). As condições necessárias são aquelas essenciais para que o aluno possa desempenhar determinado papel, ou seja, se o aluno não atender a essas condições não será possível assumir o papel estabelecido. As condições desejadas definem os requisitos que o aluno deve satisfazer para assegurar os benefícios de aprendizagem previstos. Outros elementos representados na Figura 1(a) são o comportamento de colaboração (how to collaborate); e a teoria de aprendizagem (support) que dá suporte ao papel definido. Um exemplo de papel colaborativo é o Participante Pleno (full participant) representado pela estrutura ontológica da Figura 1(b).

Figure 1: (a) Estrutura ontológica para representação dos papéis colaborativos de aprendizagem (CL Role) e (b) o papel de Participante Pleno (full participant).

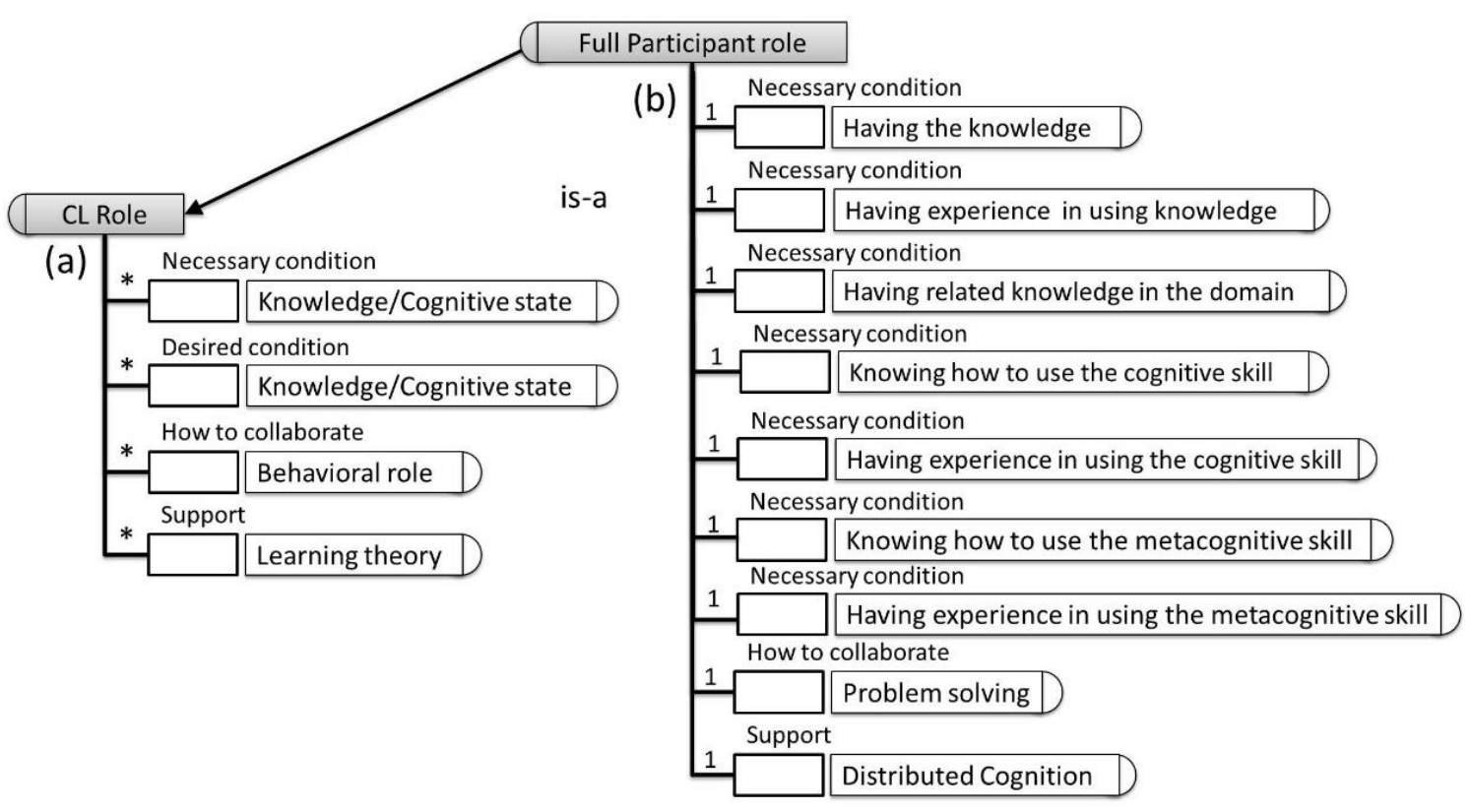

A Figura 2 apresenta uma extensão da estrutura ontológica definida por Isotani et al. (2009) (Figura 1) que incluiu os pré-requisitos afetivos (linhas tracejadas) e os novos PCAs (Figura 2(c) e (d)).

Figure 2: Estrutura ontológica para representar os novos PCAs (c e d) em cenários CSCL.

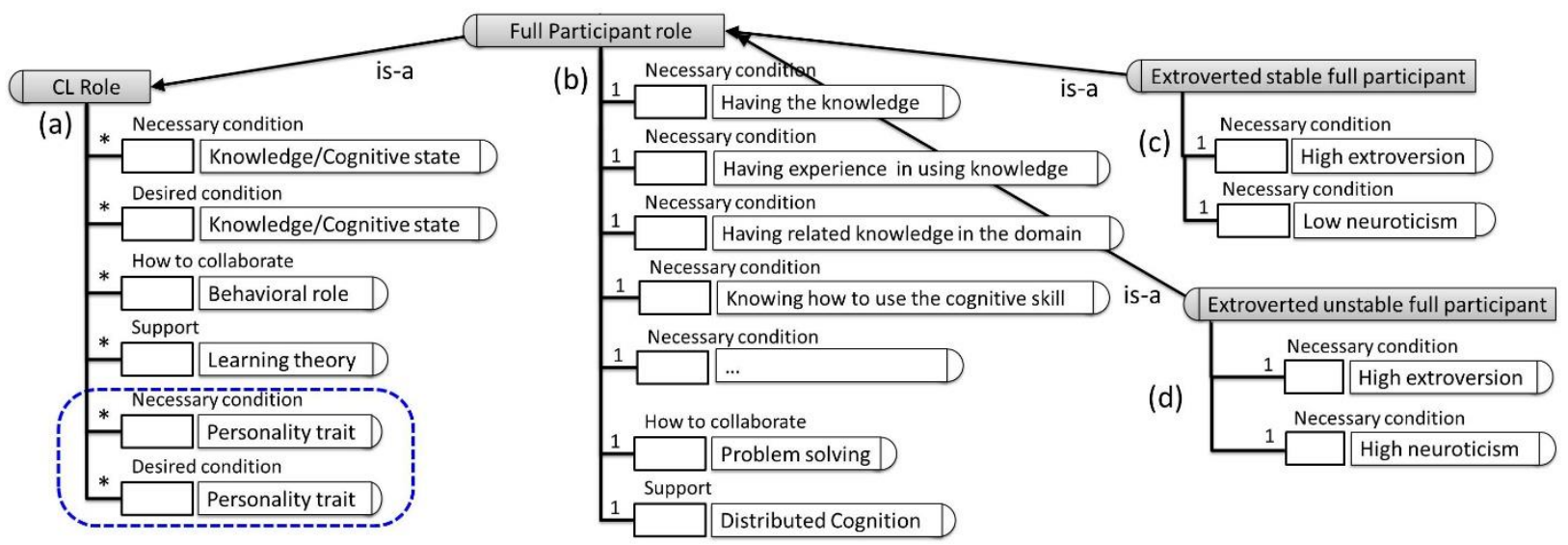

Com base na estrutura ontológica da Figura 2, foram criadas as seguintes especializações do PCA Participante Pleno (full participant) (Figura 2(b)) pertencente à teoria de aprendizagem Distributed Cognition (Salomon, 1993): Participante pleno extrovertido estável (extroverted stable full participant) (Figura 2(c)) e Participante pleno extrovertido instável (extroverted unstable full participant) (Figura 2(d)). 
A partir da estrutura ontológica definida pela Figura 2 é possível criar novas estruturas para representar os cenários de aprendizagem colaborativa com estratégias para lidar, por exemplo, com a falta de reflexão dos alunos. A Figura 3 apresenta a definição de três cenários colaborativos de aprendizagem composto pelas seguintes combinações de PCAs: (a) Participante Pleno Extrovertido Estável/Instável (Extroverted stable/unstable full participant), (b) Participante Pleno Extrovertido Estável/Estável (Extroverted stable/stable full participant), e (c) Participante Pleno Extrovertido Instável/Instável (Extroverted unstable/unstable full participant).

Figure 3: Estruturas ontológicas para representar três cenários colaborativos de aprendizagem (a) (b) (c) para lidar com o problema de falta de reflexão dos alunos na resolução de problemas.

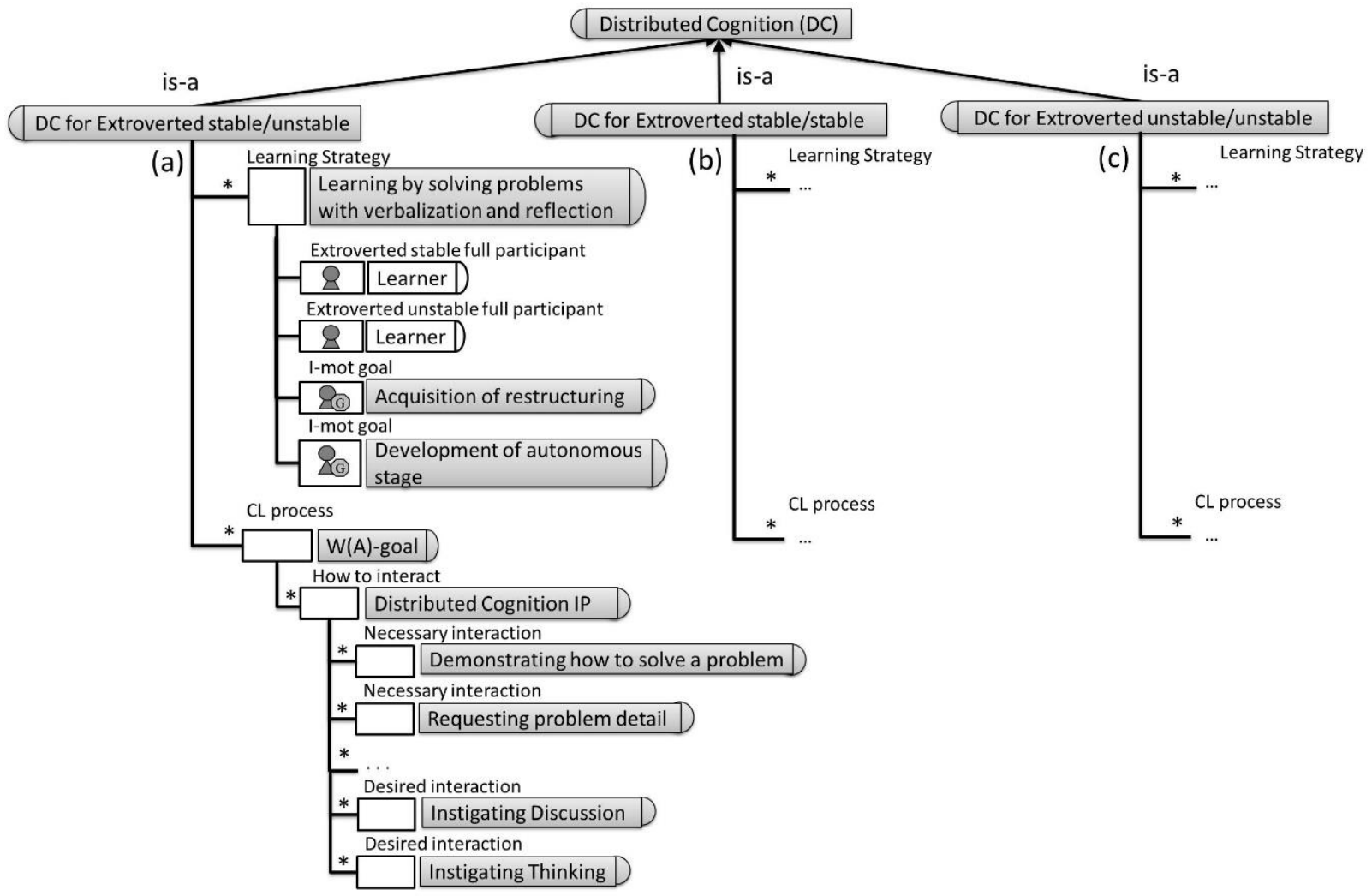

As estruturas ontológicas ilustradas pelas Figuras 3(a)(b)(c) representam três cenários de aprendizagem colaborativa baseados na teoria de aprendizagem Distributed Cognition (Salomon, 1993). Essas três estruturas adotam a mesma estratégia de aprendizagem (Learning Strategy) e o mesmo processo de colaboração (CL process), diferenciados apenas pela combinação dos PCAs desempenhados pelos alunos nos grupos de aprendizagem: (a) Extrovertido Estável/Instável (Extroverted stable/unstable), (b) Extrovertido Estável/Estável (Extroverted stable/stable), e (c) Extrovertido Instável/Instável (Extroverted unstable/unstable).

Com base na estrutura ilustrada pela Figura 3(a), os alunos que desempenharem os PCAs Participante Pleno Extrovertido Estável (Extroverted stable full participant) e Participante Pleno Extrovertido Instável (Extroverted unstable full participant) irão adotar a estratégia de aprendizagem "Aprendizagem por meio de resolução de problemas com verbalização e reflexão (Learning by solving problems with verbalization and reflection)" para lidar com a falta de reflexão dos estudantes. Vale destacar que essa estratégia é uma especialização da estratégia "Aprendizagem por meio de resolução de problemas (Learning by solving problems)".

A estrutura ontológica W(A)-goal mostrada na Figura 3(a) representa o processo de colaboração que especifica as interações necessárias e desejadas que devem ocorrer entre os alunos. Por exemplo, como interação necessária, a teoria de aprendizagem Distributed 
Cognition (Salomon, 1993) define que ocorra: 1) demonstrações de como resolver o problema (demonstrating how to solve a problem), 2) solicitações sobre detalhes do problema a ser solucionado (requesting problem detail), dentre outros. Como interação desejada a teoria recomenda incentivar a discussão (instigating discussion) e o pensamento crítico (instigating thinking) entre os membros do grupo.

Baseado na estrutura ontológica apresentada pela Figura 2 e os cenários CSCL ilustrados pela Figura 3 é possível criar sistemas "inteligentes" que automaticamente planejem cenários colaborativos de aprendizagem para lidar, por exemplo, com a falta de reflexão dos estudantes. No intuito de avaliar o impacto da característica de baixa e alta impulsividade em cada um desses cenários foi realizado um estudo de caso que é detalhado na Seção 6.

\section{Estudo de Caso}

Um estudo de caso utilizando os novos PCAs criados na Seção 4 foi desenvolvido com os alunos do Ensino Fundamental I da Escola Paidéia, localizada na cidade de Bebedouro-SP. O conteúdo abordado envolveu as operações básicas de matemática (soma e subtração) utilizando a plataforma de jogos digitais Educacross.

\subsection{Plataforma Educacross}

A plataforma Educacross (Educacross, 2016) foi desenvolvida pela empresa de inovação tecnológica Cross Reality (Cross Reality, 2016), que é composta por uma equipe multidisciplinar formada por profissionais das áreas de Psicologia, Pedagogia e Computação. A empresa tem como missão desenvolver soluções em softwares para o desenvolvimento de jogos educacionais para apoiar o ensino-aprendizagem das séries iniciais do Ensino Fundamental I. A plataforma contém atualmente jogos de matemática para as séries iniciais do ensino fundamental e ferramentas de apoio ao professor, pautados no projeto pedagógico, além de recursos de planejamento (roteiros de atividades) e monitoramento de atividades (armazenamento em arquivos de $\log$ ). A plataforma apresenta ainda sequências didáticas que pretendem cobrir as necessidades de conteúdo visto pelos alunos ao longo do ano letivo.

\subsubsection{Adaptação dos Jogos da Educacross ao Contexto Colaborativo}

Para a realização desse estudo de caso foram selecionados quatro jogos da plataforma Educacross que abordam as operações de soma e subtração com dois e três dígitos: sub sapo (níveis 4 e 6), super heroína (nível 1), mini herói (nível 4) e soma sapo (níveis 4, 5 e 6). Dado que os jogos da plataforma Educacross foram projetados para um jogador (single-player), os mesmos foram adaptados para que pudessem ser usados no contexto de colaboração conforme mostrado a seguir na descrição dos Jogos 1, 2, 3 e 4. Mais informações sobre o material usado para a realização dessas adaptações e o impacto cognitivo sobre o uso desses jogos no contexto colaborativo podem ser encontrados em Reis, Rodriguez, Lyra, Isotani, Stamato et al. (2016).

$\underline{\text { Jogo } 1 \text { - Sub sapo }}$

Um exemplo de atividade do jogo Sub sapo é mostrado na Figura 4. 
Figure 4: Exemplo de atividade do jogo Sub sapo. Adaptado de Educacross (2016).

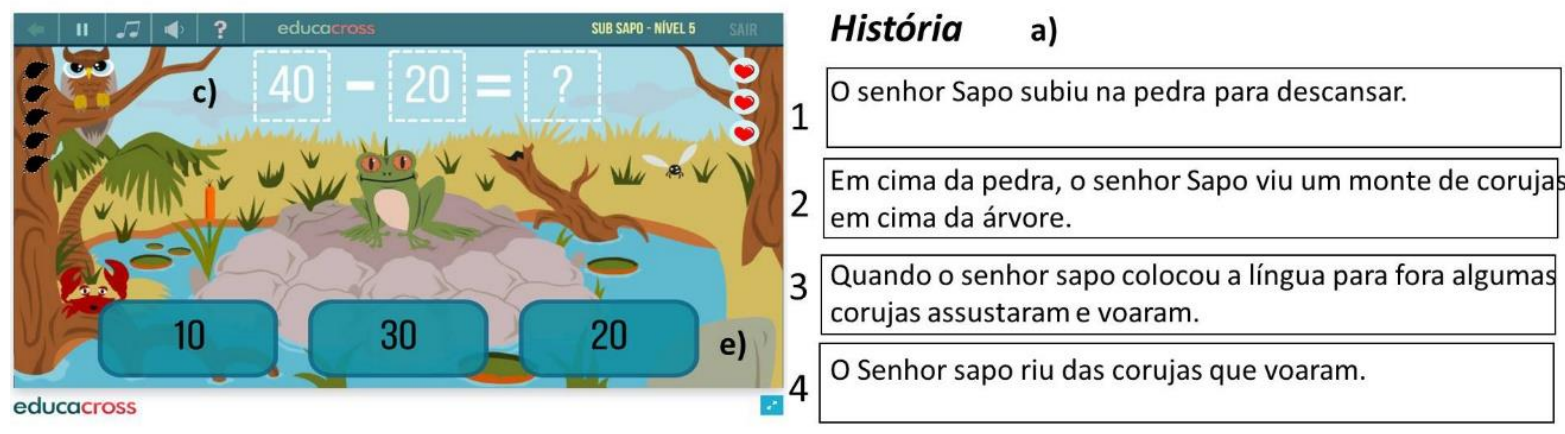

\begin{tabular}{|l|l|l|}
\hline \multirow{2}{*}{$\begin{array}{l}\text { Operação } \\
1\end{array}$} & Perguntas b) & Respostas d) \\
\cline { 2 - 3 } & Quantas corujas estavam em cima da árvore? & 40 \\
\cline { 2 - 3 } & Quantas corujas voaram depois que o senhor Sapo colocou a língua para fora? & 20 \\
\cline { 2 - 3 } & $\begin{array}{l}\text { Quantas corujas ficaram na árvore depois que o senhor Sapo colocou a língua para } \\
\text { fora? }\end{array}$ & 20 \\
\hline
\end{tabular}

Para a resolução da atividade apresentada na Figura 4 foi estabelecida a seguinte sequência de passos a serem seguidos pelos alunos:

1) Ordenar as tiras em papel para montar uma história (contexto) com base na tela de fundo do jogo (Figura 4.a);

2) Ler as perguntas apresentadas na folha de respostas (Figura 4.b);

3) Relacionar os elementos da operação matemática à história e identificar o que cada número representa (Figura 4.c);

4) Responder as perguntas na folha de respostas (Figura 4.d);

5) Selecionar uma opção para o jogo Sub sapo usando o tablet (Figura 4.e).

\section{Jogo 2 - Super heroína}

Um exemplo de atividade do jogo Super heroína é mostrado na Figura 5.

Figure 5: Exemplo de atividade do jogo Super heroína. Adaptado de Educacross (2016).

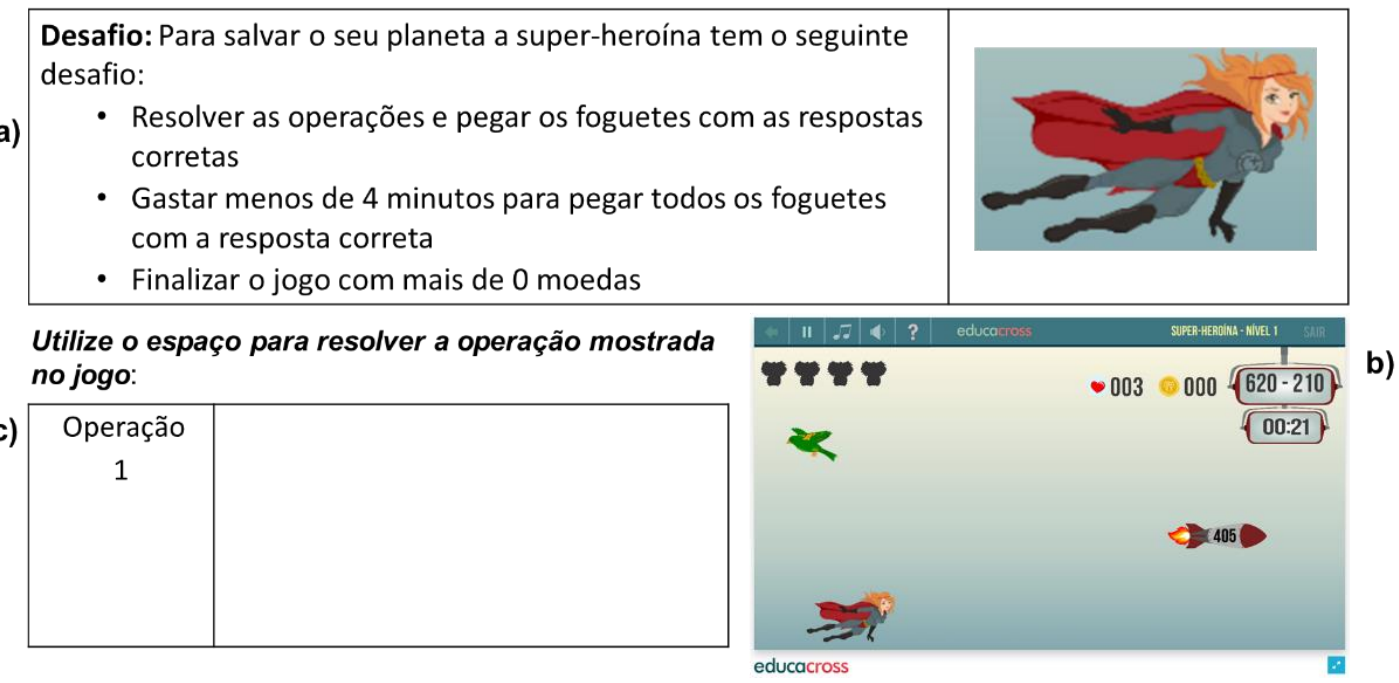

Para a resolução da atividade apresentada na Figura 5 foi estabelecida a seguinte sequência de passos a serem seguidos pelos alunos:

1) Ler o texto do desafio (Figura 5.a)

2) Para cada operação matemática: 
2.1) Um membro do grupo deve visualizar a operação na tela do jogo Super heroína usando o tablet (Figura 5.b);

2.2) O outro membro deve efetuar o cálculo da operação matemática na folha em papel (Figura 5.c);

2.3) Na operação seguinte, os membros devem trocar de posição, ou seja, um visualizar a operação na tela do jogo usando o tablet e o outro resolver a operação no papel.

2.4) Repetir os passos 2.1, 2.2, 2.3 até que finalizem as operações do jogo.

\section{Jogo 3 - Mini herói}

Um exemplo de atividade do jogo Mini herói é mostrado na Figura 6.

Figure 6: Exemplo de atividade do jogo Mini herói. Adaptado de Educacross (2016).

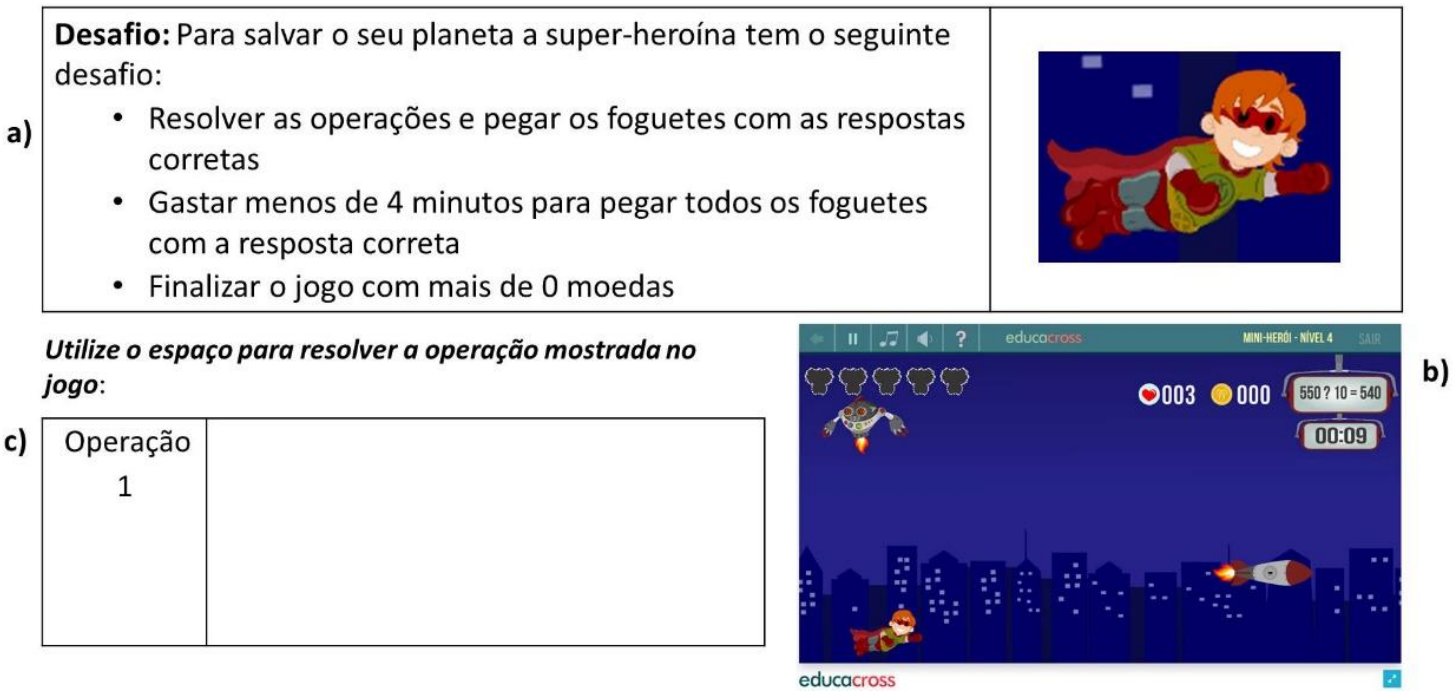

Para a resolução da atividade apresentada na Figura 6 foi estabelecida a seguinte sequência de passos a serem seguidos pelos alunos:

1) Ler o texto do desafio (Figura 6.a)

2) Para cada operação matemática:

2.1) Um membro de grupo deve visualizar a operação na tela do jogo do Mini herói usando o tablet (Figura 6.b);

2.2) O outro membro deve efetuar o cálculo da operação matemática na folha em papel (Figura 6.c);

2.3) Na operação seguinte, os membros devem trocar de posição, ou seja, um visualizar a operação na tela do jogo usando o tablet e o outro resolver a operação no papel.

2.4) Repetir os passos 2.1, 2.2, 2.3 até que finalizem as operações do jogo.

\section{$\underline{\text { Jogo } 4 \text { - Soma sapo }}$}

Um exemplo de atividade do jogo Soma sapo é mostrado na Figura 7. 
Figure 7: Exemplo de atividade do jogo Soma sapo. Adaptado de Educacross (2016).

a)

No dia seguinte o senhor Sapo decidiu voltar a floresta com a senhora Sapo, pois os dois estavam com muita fome.

Ao chegar na floresta, o senhor sapo como era mais guloso comeu mais mosquitos que a senhora Sapo.

\begin{tabular}{|c|l|l|}
\hline $\begin{array}{c}\text { Operação } \\
1\end{array}$ & Perguntas b) & Respostas d) \\
\cline { 2 - 3 } & $\begin{array}{l}\text { Quantos mosquitos o senhor Sapo } \\
\text { comeu? }\end{array}$ & 21 \\
\cline { 2 - 3 } & $\begin{array}{l}\text { Quantos mosquitos a senhora Sapo } \\
\text { comeu? }\end{array}$ & 14 \\
\cline { 2 - 3 } & $\begin{array}{l}\text { Quantos mosquitos no total o senhor } \\
\text { Sapo e a senhora Sapo comeram? }\end{array}$ & 35 \\
\hline
\end{tabular}

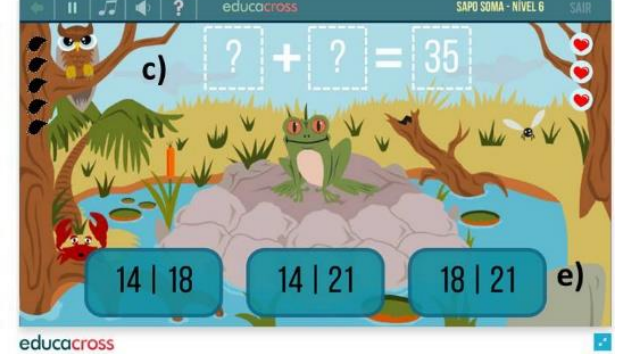

Para a resolução da atividade apresentada na Figura 7 foi estabelecida a seguinte sequência de passos a serem seguidos pelos alunos:

1) Ler o texto (Figura 7.a) e as perguntas elaboradas (Figura 7.b);

2) Visualizar a operação matemática apresentada na tela do jogo usando o tablet (Figura 7.c) e identificar o que cada elemento da operação representa com base no texto lido (Figura 7.a);

3) Responder as perguntas elaboradas (Figura 7.d);

4) Selecionar uma opção no jogo Soma sapo usando o tablet (Figura 7.e);

4.1) No caso de resposta incorreta, os alunos devem repetir os passos 3 e 4.

5) Repetir os passos 2, 3 e 4 até que encerrem as operações no jogo Soma sapo.

\subsection{Participantes}

O estudo de caso foi realizado com um grupo de 18 alunos do $5^{\circ}$ ano do Ensino Fundamental I. Desse grupo, três alunos possuem transtorno do espectro autista e, apesar de participarem das atividades, não foram considerados para efeito de análise, dado que os testes (personalidade e conhecimento) tiveram que ser adaptados ao estágio dessas crianças e aplicados com o auxílio das professoras da turma. Portanto, são considerados participantes do estudo 15 estudantes, sendo nove do sexo feminino e seis estudantes do sexo masculino, na faixa de idade compreendida entre 9 e 10 anos.

\subsection{Fases}

O presente estudo de caso foi dividido em quatro fases: A) Pré-teste, B) Intervenção, C) Pósteste, e D) Teste de Retenção, conforme ilustrado pela Figura 8.

Figure 8: Fases do Estudo de Caso.

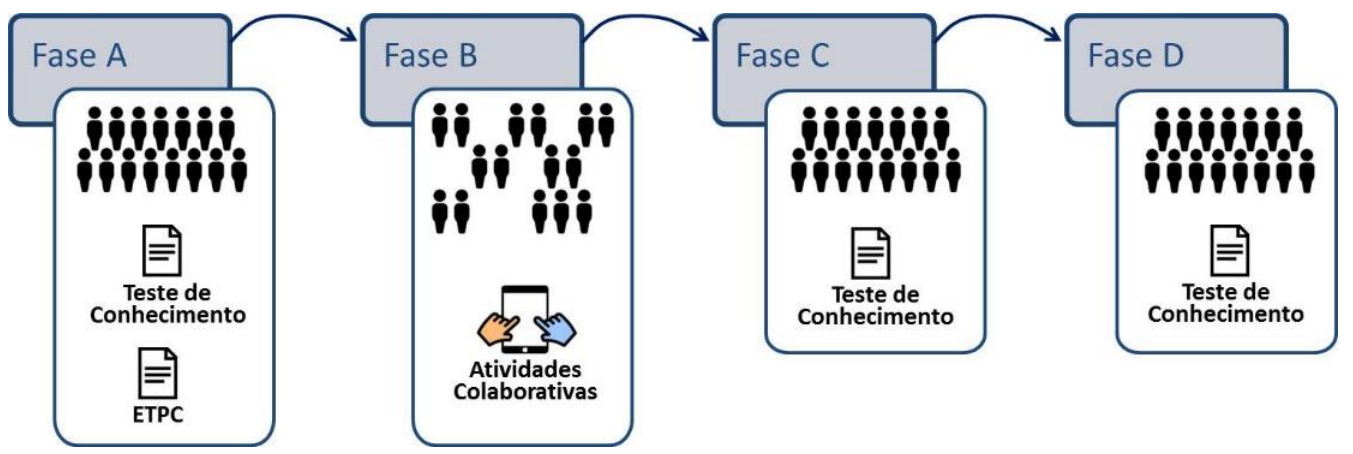


Conforme mostrado na Figura 8, na fase A os participantes foram submetidos a resolução de dois testes individuais: pré-teste de conhecimento e questionário de personalidade (ETPC). Na fase B os estudantes foram orientados sobre as atividades a serem desenvolvidas durante a sessão colaborativa e agrupados em duplas/trio para resolução das operações de soma e subtração utilizando a plataforma Educacross (Educacross, 2016). Na fase C, os participantes responderam individualmente ao pós-teste de conhecimento para avaliação da aprendizagem resultante da sessão colaborativa. Finalmente, na fase $\mathrm{D}$ os participantes responderam individualmente ao teste de retenção para avaliar o conhecimento fixado pelos alunos sobre as operações matemáticas de soma e subtração. Os testes realizados nas fases A, C e D foram resolvidos em papel e as atividades da fase $\mathrm{B}$ foram desenvolvidas usando o tablet e papel.

\subsubsection{Fase $A$}

No primeiro encontro, os participantes foram submetidos à resolução de dois testes individuais realizados em papel. No teste de personalidade, os 15 participantes responderam ao questionário psicológico ETPC (Escala de Traços de Personalidade para Crianças) (Sisto, 2004), composto por 30 questões específicas sobre o comportamento adotado por crianças na faixa de idade entre 05 e 10 anos, em situações cotidianas. A aplicação do teste foi coletiva e o tempo limite de resposta foi de $15 \mathrm{~min}$. O pré-teste de conhecimento, composto por quatro exercícios avaliou o conhecimento inicial dos alunos sobre as operações básicas de matemática. Os exercícios contemplaram operações de soma e subtração de dois e três dígitos, multiplicação por dois e divisão por dois. O tempo limite para resolução do teste foi de 20 min.

\subsubsection{Fase B}

No segundo encontro, realizado no intervalo de sete dias, antes de iniciar a intervenção, os pesquisadores orientaram os participantes sobre a dinâmica das atividades a serem realizadas na plataforma Educacross (um tablet por grupo) e nas folhas de respostas. Na sequência, os alunos foram organizados em 6 duplas e 1 trio de acordo com os resultados dos traços de personalidade extrovertido instável/estável e os resultados do pré-teste de conhecimento (Fase A).

Durante a intervenção, os grupos trabalharam em quatro atividades da plataforma Educacross descritas na Seção 6.1.1. O tempo limite para resolução de cada uma das atividades variou em torno de $30 \mathrm{~min}-1 \mathrm{~h}$.

No intuito de coletar dados sobre as interações dos alunos durante a intervenção, foi utilizado um roteiro de observação e três câmeras filmadoras. Participaram da sessão colaborativa três observadores, sendo que dois ficaram responsáveis por observar duas duplas cada e um observador responsável por duas duplas e um trio. Os grupos interagiram livremente e podiam contar com a ajuda dos observadores, caso tivessem alguma dúvida específica sobre o desenvolvimento da atividade.

\subsubsection{Fase $C$}

Ao final da Fase B (intervenção) os alunos responderam individualmente o pós-teste de conhecimento (em papel), composto por três exercícios envolvendo as operações de soma e subtração de dois e três dígitos e um exercício de interpretação (Figura 9) similar às atividades desenvolvidas pelos alunos. O tempo limite para resolução do pós-teste foi de 15 min. 
Figura 9: Exemplo de exercício de interpretação.

No final da tarde, o senhor Sapo resolveu voltar para casa.
No caminho de volta para casa o senhor Sapo encontrou
várias moedas no chão.
Algumas moedas escorregaram e caíram no lago.

Resolva a operação abaixo e responda as questões:

$$
?-5=5
$$

\begin{tabular}{|l|l|}
\hline Quantas moedas o senhor Sapo encontrou no chão? & \\
\hline Quantas moedas caíram no lago? & \\
\hline Quantas moedas sobraram na mão do senhor Sapo? & \\
\hline
\end{tabular}

\subsubsection{Fase D}

No terceiro encontro (realizado com intervalo de sete dias do pós-teste), foi aplicado um teste de retenção composto por três exercícios envolvendo as operações de soma e subtração de dois e três dígitos e um exercício de interpretação (Figura 9). O tempo limite para resolução do teste de retenção foi de 15 min.

\subsection{Resultados}

Nesse estudo dois grupos de trabalho (uma dupla e um trio) foram excluídos dos resultados uma vez que não foi possível extrair os dados para efeito de análise. No caso da dupla, o resultado do teste psicológico de ambos os membros foi indefinido e, no caso do trio, uma das alunas se isolou (recusando a participar das atividades) e, por conta disso, os outros dois estudantes passaram mais tempo tentando incluir o colega na interação, do que trabalhando na atividade propriamente dita. Dessa forma, os resultados apresentados nesta seção referem-se aos dados da interação de 5 duplas, coletados durante a fase B, de Intervenção. Os resultados obtidos a partir dos testes aplicados nas fases A, C e D e os dados coletados na fase B, por meio do roteiro de observação e câmeras filmadoras, estão sumarizados na Tabela 4.

Tabela 4: Resumo dos resultados do estudo de caso.

\begin{tabular}{|c|c|c|c|c|c|}
\hline $\begin{array}{c}\text { ID } \\
\text { Aluno }\end{array}$ & PCA & $\begin{array}{l}\text { Conhecimento } \\
\text { Adquirido }\end{array}$ & $\begin{array}{c}\text { Habilidade Cognitiva } \\
\text { Adquirida }\end{array}$ & $\begin{array}{c}\text { Impulsividade } \\
\text { durante a sessão } \\
\text { colaborativa } \\
\end{array}$ & $\begin{array}{c}\text { Impulsividade afetou } \\
\text { negativamente a } \\
\text { performance do grupo? }\end{array}$ \\
\hline E1a & PPEI & Não & Sim & Não & \multirow[t]{2}{*}{ Não } \\
\hline E1b & PPEE & Sim & Sim & Sim (baixa) & \\
\hline E2a & PPEI & Não & Não & Sim (alta) & \multirow[t]{2}{*}{ Sim } \\
\hline $\mathrm{E} 2 \mathrm{~b}$ & PPEE & Sim & Não & Não & \\
\hline E3a & PPEI & Não & Não & Não & \multirow[t]{2}{*}{-} \\
\hline $\mathrm{E} 3 \mathrm{~b}$ & PPEI & Não & Sim & Não & \\
\hline $\mathrm{E} 4 \mathrm{a}$ & PPEI & Não & Não & Não & \multirow[t]{2}{*}{-} \\
\hline $\mathrm{E} 4 \mathrm{~b}$ & PPEI & Sim & Sim & Não & \\
\hline E5a & PPEE & Sim & Sim & Sim (baixa) & \multirow[t]{2}{*}{ Não } \\
\hline $\mathrm{E} 5 \mathrm{~b}$ & PPEE & Sim & Sim & Não & \\
\hline
\end{tabular}

A primeira coluna da Tabela 4, "ID Aluno", representa a identificação individual dos participantes. Para facilitar a identificação dos grupos foi utilizada a numeração de 1 a 5 . Por exemplo, Grupo 1 (E1a e E1b) e Grupo 2 (E2a e E2b). 
A segunda coluna, " $P C A$ ", representa o papel colaborativo afetivo desempenhado por cada um dos participantes na sessão colaborativa, sendo PPEI a sigla para Participante Pleno Extrovertido Instável e PPEE para Participante Pleno Extrovertido Estável.

As colunas 3 "Conhecimento Adquirido" e 4 "Habilidade Cognitiva" têm como proposta apresentar se os benefícios de aprendizagem previstos pela teoria de aprendizagem Distributed Cognition (Tabela 2, coluna 4), foram alcançados ou não. O "Conhecimento Adquirido" (coluna 3) foi medido com base na análise dos testes de conhecimento aplicados nas fases A, C e D. Por exemplo, se o aluno deixou de cometer algum dos erros de soma e subtração no pós-teste (fase $\mathrm{C}$ ) e isso se manteve no teste de retenção (fase D), foi definido que Sim, o(a) aluno(a) adquiriu novo conhecimento; caso contrário, Não. Vale ressaltar que os alunos E1a, E3a, E3b acertaram todas as questões de todos os três testes de conhecimento, aplicados nas fases A, C e D. O desenvolvimento da "Habilidade Cognitiva" (coluna 4) foi avaliado pelos exercícios de interpretação (e.g., Figura 9) colocados no pós-teste e teste de retenção (fases B e C). Aos alunos que acertaram os exercícios em ambos os testes foi atribuído Sim; caso contrário, Não.

A coluna 5, "Impulsividade durante a sessão colaborativa", mostra os estudantes que apresentaram ou não impulsividade durante a interação. Um indivíduo foi caracterizado com alta impulsividade se o tempo de latência entre as perguntas e respostas foi baixo e o número de respostas incorretas foi maior ou igual a $50 \%$. No caso do número de respostas incorretas menor que $50 \%$, a impulsividade foi baixa.

Finalmente, a coluna 6, "Impulsividade prejudicou a performance do estudante na interação com o grupo?", avalia os grupos em que pelo menos um dos membros manifestou impulsividade durante a intervenção. Essa análise foi feita com base na forma em que os membros do grupo lidaram com a questão da impulsividade, ou seja, se a falta de reflexão foi resolvida pelos membros do grupo, então a impulsividade Não afetou negativamente a performance do grupo; caso contrário, Sim.

\subsection{Análise e Discussão dos Resultados}

Nesta seção apresentamos a análise e discussão dos resultados com bases em três hipóteses alternativas.

- Hipótese Alternativa 1: Em grupos com PCAs homogêneos, em que todos os membros desempenham o papel de participante pleno extrovertido estável, a característica de baixa impulsividade é prejudicial se pelo menos um dos membros manifestá-la durante a sessão colaborativa.

De acordo com a Tabela 4, apenas o Grupo 5 foi formado por membros que desempenharam o PCA participante pleno extrovertido estável (PPEE). Nesse grupo apenas o membro E5 manifestou baixa impulsividade e essa característica não prejudicou a sua performance na interação com o grupo. Nesse caso, os membros realizaram os cálculos das operações sem recorrer ao auxílio da folha de respostas, com a diferença do membro E5a sempre dar a resposta mais rápida e algumas vezes incorreta. Após os primeiros erros cometidos, o aluno E5a adotou a estratégia de sempre confirmar sua resposta com o colega E5b antes de prosseguir na atividade.

Com base na análise do Grupo 5, os dados coletados mostraram indícios de que a característica de baixa impulsividade não afetou negativamente a performance do grupo. Logo, a hipótese 1 não pode ser aceita.

- Hipótese Alternativa 2: Em grupos com PCAs homogêneos, em que todos os membros desempenham o papel de participante pleno extrovertido instável, a característica de alta 
impulsividade é prejudicial se pelo menos um dos membros manifestá-la durante a sessão colaborativa.

De acordo com a Tabela 4, dois grupos tiveram membros que desempenharam o PCA participante pleno extrovertido instável (PPEI): Grupos 3 e 4.

Nos Grupos 3 e 4 apesar de ambos os membros apresentarem individualmente alta impulsividade, essa característica não se manifestou durante a sessão colaborativa. Logo, a hipótese 2 não pode ser confirmada nem refutada.

- Hipótese Alternativa 3: Em grupos com PCAs heterogêneos, quando os membros desempenham os PCAs participante pleno extrovertido estável e participante pleno extrovertido instável, as características de baixa ou alta impulsividade prejudicam a performance do grupo se pelo menos um dos membros manifestar uma dessas características durante a sessão colaborativa.

De acordo com a Tabela 4, dois grupos tiveram membros que desempenharam os PCAs participante pleno extrovertido estável (PPEE) e participante pleno extrovertido instável (PPEI): Grupos 1 e 2.

No Grupo 1, a característica de impulsividade não se manifestou no membro E1a (PPEI) durante a sessão colaborativa. Por outro lado, apesar do indivíduo E1b (PPEE) ter apresentado baixa impulsividade, isso não prejudicou a sua performance na interação com o colega.

No Grupo 2, a característica de impulsividade não se manifestou no membro E2b (PPEE) durante a sessão colaborativa. No caso do membro E2a (PPEI), o mesmo apresentou alta impulsividade e foi observado que esse comportamento afetou negativamente a sua interação com o colega. Essa observação foi feita com base no comportamento do aluno E2a em sempre apresentar respostas rápidas e incorretas para as operações matemáticas e na sua recusa em desenvolver as operações no papel a pedido do colega E2b. Esse comportamento acarretou em várias discussões entre os membros que não conseguiam chegar a um acordo. Além disso, o colega E2b se mostrou bastante irritado com o comportamento do colega E2a alterando o tom de voz e tomando o tablet da mão do colega por várias vezes.

Como a característica de impulsividade se manifestou em pelo menos um dos membros dos Grupos 1 e 2, e esse elemento hora afetou e hora não a performance do grupo, a hipótese 3 não pode ser confirmada nem refutada.

\section{Conclusão}

Este trabalho teve como objetivo ampliar a estrutura ontológica de Papéis Colaborativos Afetivos (PCAs) definida por Reis, Rodriguez, Challco et al. (2015) e Reis, Rodriguez, Lyra, Challco et al. (2016) para representar a relação entre os traços de personalidade extrovertido estável/instável (Sisto, 2004) e o papel colaborativo participante pleno (full participant) pertencente a teoria de aprendizagem Distributed Cognition (Salomon, 1993). A partir dessa relação espera-se que aplicações computacionais inteligentes (e.g., sistemas tutores) possam automaticamente criar e planejar cenários colaborativos de aprendizagem para lidar, por exemplo, com a falta de reflexão dos estudantes.

No intuito de avaliar o impacto das características de alta e baixa impulsividade na formação de grupos de aprendizagem homogêneos e heterogêneos em cada um dos cenários de colaboração da Figura 3, foi desenvolvido um estudo de caso envolvendo 15 crianças do $5^{\mathrm{a}}$ ano do Ensino Fundamental I, na faixa de 9-10 anos. Os resultados mostraram indícios de que a característica de baixa impulsividade não influenciou negativamente a performance do grupo cujos integrantes possuíam PCA homogêneo (extrovertido estável) (hipótese 1). Por outro lado, 
a hipótese 2 que avaliou o impacto da característica de alta impulsividade na performance dos integrantes de grupos homogêneos com PCA extrovertido instável, não pode ser confirmada ou refutada, dado que nenhum dos integrantes manifestou essa característica durante a sessão colaborativa. Por fim, a hipótese 3 que investigou a influência da característica de impulsividade (alta ou baixa) na performance de grupos com PCAs heterogêneos (extrovertido estável e extrovertido instável) também não pode ser confirmada ou refutada, dado que os resultados foram contraditórios.

Dado que não foi possível aplicar testes estatísticos, devido ao número reduzido de participantes, sugere-se como trabalho futuro evoluir o estudo de caso para um experimento controlado, que mantenha as configurações de um ambiente real de aprendizagem. Recomendase também que o experimento possua uma amostra de participantes de larga escala para que seja possível aplicar métodos estatísticos que confirmem ou refutem as hipóteses elaboradas.

Além disso, pretende-se incluir os traços de personalidade psicoticismo e sociabilidade, avaliados pelo teste de personalidade ETPC, às próximas análises para investigar se as características desses traços podem ser responsáveis por inibir ou minimizar a característica de impulsividade no trabalho em grupo em indivíduos que apresentaram alta impulsividade no teste psicológico.

\section{Agradecimentos}

Os autores agradecem ao CNPq pelo apoio financeiro e a colaboração da Escola Paidéia, em especial, da coordenadora Neli Volpini e das professoras Patrícia e Léia.

\section{Referências}

Allport, G. W. (1927). Concepts of trait and personality. Psychological Bulletin, 24, 284-293.

Bidjerano, T., \& Dai, D. Y. (2007). The relationship between the big-five model of personality and self-regulated learning strategies. Learning and Individual Differences, 17, 69-81. doi: $\underline{10.1016 / j . l i n d i f .2007 .02 .001}$ [GS Search]

Bittencourt, I. I., \& Costa, E. (2011). Modelos e Ferramentas para a Construção de Sistemas Educacionais Adaptativos e Semânticos. Revista Brasileira de Informática na Educação, 19(1), 85-98. doi:10.5753/RBIE.2011.19.01.85 [GS Search]

Borst, W. (1997). Construction of Engineering Ontologies for Knowledge Sharing and Reuse. PhD thesis, University of Twente, P.O. Box 217 - 7500 AE Enschede - The Netherlands. [GS Search]

Challco, G. C., Moreira, D. A., Bittencourt, I. I., Mizoguchi, R., \& Isotani, S. (2015). Personalization of Gamification in Collaborative Learning Contexts using Ontologies. IEEE Latin America Transactions, 13(6), 1995-2002. doi: 10.1109/TLA.2015.7164227 [GS Search]

Cross Reality. Disponível em < $\underline{\text { http://www.crossreality.com.br/> }}$. Acesso em 02 de março de 2017.

Davidson, B., Gillies, R. A., \& Pelletier, A. L. (2015). Introversion and Medical Student Education: Challenges for Both Students and Educators. International Journal on Teaching and Learning in Medicine, 27(1), 99-104. doi: 10.1080/10401334.2014.979183 [GS Search] 
Dicheva, D., Sosnovsky, S., Gavrilova, T., \& Brusilovsky, P. (2005, July). Ontological Web portal for educational ontologies. In Proceedings of the International Workshop on Applications of Semantic Web Technologies for E-Learning, 1-9. [GS Search]

Dillenbourg, P. (2002). Over-Scripting CSCL: The Risks of Blending Collaborative Learning with Instructional Design. In Three worlds of CSCL. Can we support CSCL?. Heerlen: Open University Nederland, 61-91. [GS Search]

Dillenbourg, P., Järvelä, S., \& Fischer, F. (2009). The Evolution of Research on ComputerSupported Collaborative Learning. In N. Balacheff, S. Ludvigsen, T. de Jong, A. Lazonder, \& S. Barnes (Eds.), Technology-Enhanced Learning, (pp. 3-19). Springer Netherlands. doi: 10.1007/978-1-4020-9827-7_1 [GS Search]

Educacross. A plataforma da Educação Inteli-gente. Disponível em

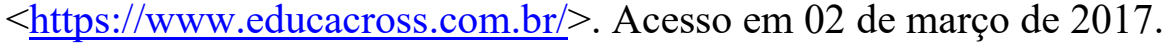

Gruber. T. R. (1993). A Translation Approach to Portable Ontology Specification. Knowledge Acquisition, 5, 199-220. [GS Search]

Huitt, W. G. (1992). Problem Solving and Decision Making: Consideration of Individual Differences Using the Myers-Briggs Type Indicator. Journal of Psychological Type, 24, 3344, 1992. [GS Search]

Inaba, A., Ikeda, M., \& Mizoguchi, R. (2003, July). What Learning Patterns are Effective for a Learner's Growth?. In Proceeding of the International Conference on Artificial Intelligence in Education, 219-226. [GS Search]

Inaba, A., \& Mizoguchi, R. (2004, August). Learner's Role and Predictable Educational Benefits in Collaborative Learning. In Proceeding of the International Conference on Intelligent Tutoring Systems, LNCS 3220, 285-294, Springer-Verlag. [GS Search]

Inaba, A., Supnithi, T., Ikeda, M., \& Mizoguchi, R. (2000, June). How Can We Form Effective Collaborative Learning Groups. In Proceeding of the International Conference on Intelligent Tutoring Systems, LNCS 1839, 282-291. doi: 10.1007/3-540-45108-0 32 [GS Search]

Isotani, S., Inaba, A., Ikeda, M., \& Mizoguchi, R. (2009). An Ontology Engineering Approach to the Realization of Theory-Driven Group Formation. International Journal of ComputerSupported Collaborative Learning, Springer, 4(4), 445-478. doi: 10.1007/s11412-0099072-x [GS Search]

Isotani, S., \& Mizoguchi, R. (2007). Planejamento e Analise de Sessões colaborativas Utilizando Teorias de Aprendizagem e Ontologias. Revista Brasileira de Informática na Educação, 15(2), 45-56. [GS Search]

Isotani, S., Mizoguchi, R., Isotani, S., Capeli, O. M., Isotani, N., de Albuquerque, A. R. P. L., Bittencourt, I. I., \& Jaques, P. (2013). A Semantic Web-based authoring tool to facilitate the planning of collaborative learning scenarios compliant with learning theories. Computers \& Education. 63, 267-284. doi: 10.1016/j.compedu.2012.12.009 [GS Search]

Jaques, P. A., \& Nunes, M. A. S. N. (2012). Ambientes Inteligentes de Aprendizagem que inferem, expressam e possuem emoções e personalidade. In S. Isotani \& F. C. A. Campos. (Org.). Jornada de Atualização em Informática na Educação- JAIE 2012., 1, 32-71, Porto Alegre. [GS Search]

Kobbe, L., Weinberger, A., Dillenbourg, P., Harrer, A., Hamalainen, R., \& Fischer, F. (2007). Specifying Computer-Supported Collaboration Scripts. International Journal of Computer- 
Supported Collaborative Learning, 2(2-3), 211-224. doi:10.1007/s11412-007-9014-4 [GS Search]

Longhi, M. T., Reateagui, E. B., Bercht, M., \& Behar, P. A. (2007). Um estudo sobre os fenômenos afetivos e cognitivos em interfaces para softwares educativos. Revista Novas Tecnologias na Educação, 5, 1-10. [GS Search]

Mizoguchi, R. (2003). Tutorial on ontological engineering. New Generation Computing-Tokio, 21(4), 363-364.

Mizoguchi, R., Sunagawa, E., Kozaki, K., \& Kitamura, Y. (2007). The model of roles within an ontology development tool: Hozo. Applied Ontology, 2(2), 159-179. [GS Search]

Moreira, M. A. (1995). Teorias de Aprendizagens. EPU, São Paulo.

Pacheco, L., \& Sisto, F. F. (2003). Aprendizagem por interação e traços de personalidade. Psicologia Escolar e Educacional, 7(1), 69-76. [GS Search]

Reis, R. C. D., Rodriguez, C. L., Challco, G. C., Jaques, P. A., Bittencourt, I. I., \& Isotani, S. (2015, Outubro). Relação entre os Estados Afetivos e as Teorias de Aprendizagem na Formação de Grupos em Ambientes CSCL. Anais do XXV Simpósio Brasileiro de Informática na Educação, 1012-1021. doi: 10.5753/cbie.sbie.2015.1012 [GS Search]

Reis, R. C. D., Rodriguez, C. L., Lyra, K. T., Challco, G. C., Jaques, P. A., Bittencourt, I. I., \& Isotani, S. (2016). Step Towards a Model to Bridge the Gap between Personality Traits and Collaborative Learning Roles. Journal Interaction Design and Architecture(s) Journal $(I x D \& A), 28,124-144$. [GS Search]

Reis, R. C. D., Rodrigues, C. L., Lyra, K. T., Jaques, P. A., Bittencourt, I. I., \& Isotani, S. (2015, July). Affective States in CSCL Environments: A Systematic Mapping of the Literature. In: IEEE 15th International Conference on Advanced Learning Technologies (ICALT), Hualien, 335-339. doi: 10.1109/ICALT.2015.95 [GS Search]

Reis, R. C. D., Rodriguez, C. L., Lyra, K. T., \& Isotani, S. (2016, Outubro). Investigando o Impacto da Característica de Impulsividade na Aprendizagem Colaborativa com Suporte Computacional. Anais do XXVII Simpósio Brasileiro de Informática na Educação, 12351244. doi: $\underline{10.5753 / \text { cbie.sbie.2016.1235 [GS Search] }}$

Reis, R. C. D., Rodriguez, C. L., Lyra, K. T., Isotani, S., Stamato, E., \& Gotardo, R. (2016, Outubro). Experiência de Uso de Jogos Educacionais Digitais Individuais em Contextos de Colaboração. In: XXII Workshop de Informática na Escola, 485 - 494. doi: $\underline{10.5753 / \text { cbie.wie.2016.485 [GS Search] }}$

Romo, B. S., Guilherme, R. I., \& Queiroz, J. (2013, Novembro). Uma arquitetura multiagente para sistemas Web semântico para gestão de conteúdos educacionais. II Congresso Brasileiro de Informática na Educação (CBIE 2013), 561-570. doi: 10.5753/CBIE.WCBIE.2013.561 [GS Search]

Salomon, G. (1993). Distributed Cognitions. Cambridge University Press.

Scherer, K. (2005). What are emotions? And how can they be measured?. Social Science Information, 44 (4), 695-729. [GS Search]

Sisto, F. F. (2004). Escala de Traços de Personalidade para Crianças (1ª ed.). SP: Vetor. [GS Search]

Vaz, M. (2005). Aprender a pensar: o papel da metacognição na problemática da impulsividade - um estudo de caso. Monografia na área de psicologia clínica. Instituto Superior da Maia, Portugal. 